\title{
Drug safety of systemic treatments for psoriasis: results from The German Psoriasis Registry PsoBest
}

\author{
K. Reich ${ }^{1}$ U. Mrowietz ${ }^{2}$ M. A. Radtke ${ }^{3}$ D. Thaci ${ }^{4} \cdot$ S. J. Rustenbach ${ }^{3}$. \\ C. Spehr $^{3} \cdot$ M. Augustin ${ }^{3}$
}

Received: 19 November 2014/Revised: 22 June 2015/ Accepted: 11 August 2015/Published online: 10 September 2015

(C) The Author(s) 2015. This article is published with open access at Springerlink.com

\begin{abstract}
The German Psoriasis Registry PsoBest was conducted in 2008 in order to investigate the long-term outcomes and safety of systemic treatments for moderateto-severe psoriasis. Safety analysis of antipsoriatic drugs with special focus on serious adverse events (SAE) for infections, malignancies and major cardiac events (MACE) was done. Nationwide non-interventional patient treatment registry conducted in 251 active dermatology centers. Until June $2012, n=2444$ patients [ $40 \%$ female; mean age 47.3 (SD 14.1) years; mean duration of disease 18.2 (SD 14.7) years] were recruited, including $n=1791$ patients (3842 patient years) with conventional systemic drugs and $n=908$ (3442 patient years) with biological drugs. Mean PASI (Psoriasis Area and Severity Index) at inclusion was 14.7, mean DLQI (Dermatology Life Quality Index) 11.1, mean BMI (Body Mass Index) 28.2. The overall rate of SAE per 100 patient years were 1.3 (SD 0.9) per 100 patient years in conventional systemic and 1.5 (SD 1.2) in biologics ( $p>0.5$, no significant difference). The rates per 100 patient years for single severe adverse events were as follows (systemic/biologics): serious infections, 0.33/0.65
\end{abstract}

\footnotetext{
K. Reich

reich@dermatologikum.de

Dermatologikum Hamburg, Hamburg, Germany

2 Department of Dermatology, Venereology and Allergy, Psoriasis Center, University Medical Center SchleswigHolstein, Campus Kiel, Kiel, Germany

3 Institute for Health Services Research in Dermatology and Nursing (IVDP), University Medical Center HamburgEppendorf, Hamburg, Germany

4 Excellence Center for Inflammation Medicine, University Medical Center Schleswig-Holstein, Campus Lübeck, Lübeck, Germany
}

[CI (confidence interval) 0.13-0.54/0.35-0.98]; MACE, 0.56/0.77 (CI 0.29-0.97/0.41-1.31); malignancies (except non-melanoma skin cancer), $0.46 / 0.49$ (CI $0.22-0.84 /$ $0.21-0.97)$. There were no significant differences between single drugs in any of the safety parameters. The conventional systemic and biologic drugs for psoriasis show satisfying safety under routine psoriasis care in Germany with respect to infections, MACE and malignancies.

Keywords Drug safety - Pharmacovigilance - Psoriasis . Systemic treatment $\cdot$ Biologic treatment $\cdot$ Registry

\section{Introduction}

According to evidence-based guidelines, systemic drugs are treatments of choice for patients with moderate-tosevere psoriasis $[13,16]$. In most countries, first-line systemic treatment includes methotrexate, ciclosporin A and retinoids, whereas the second-line treatment is based on the biologics infliximab, etanercept, ustekinumab and adalimumab for plaque type psoriasis and psoriatic arthritis, and golimumab for psoriatic arthritis. Only in Germany fumaric acid esters (FAE) are licensed for first-line treatment. Showing a chronic, persisting course of disease, psoriasis requires a long-term strategy for treatment over many decades $[2,3]$.

The German Psoriasis Registry PsoBest records safety, long-term efficacy, patient benefit and treatment regimens of psoriasis. Patients with moderate or severe psoriasis are included in PsoBest, when treatment with a conventional systemic agent or biologic is started for the first time. Observation time is extended to 10 years.

One of the major objectives of the patient registry PsoBest is the evaluation of safety and outcomes in 
systemic treatment of plaque type psoriasis and psoriatic arthritis [4]. The present analysis presents long-term safety outcomes from PsoBest with a special focus on severe infections, malignancies and major adverse cardiovascular events (MACE). The questions addressed were as follows:

1. How is the overall safety of conventional systemic drugs and biologics in the treatment of moderate-tosevere psoriasis and psoriatic arthritis?

2. In particular, are there any differences between the various treatments with respect to safety signals on severe infections, malignancies and MACE?

\section{Materials and methods}

\section{Patient registry}

All patients considered in the analysis were observed in The German Psoriasis Registry PsoBest [4]. This patient registry includes adult patients with moderate-to-severe psoriasis at the time point of a new drug to be started. The observation time for the patient is 10 years regardless of the treatment applied. Follow-up visits in the dermatology office are conducted in intervals of 3 months in the first half-year and every 6 months afterwards. In addition, 3 months after the physician visits, the patients are directly approached by mail for further information on the treatment status and patient reported outcomes. Patients without at least one follow-up visit are excluded from analysis, because of missing validation of therapy information. Patients were assigned to biologic cohort when they have been registered on adalimumab, etanercept, infliximab or ustekinumab. Starting a conventional systemic treatment with ciclosporin, fumaric acid ester or methotrexate, patients were referred to systemic treatment.

The outcomes measured in PsoBest follow the European consensus in the PsoNet network [14, 17, 18] and are thus harmonized with patient registries on psoriasis from other countries. Moreover, the assessment of safety has been adapted to the German registry on biologics and rheumatoid arthritis [19] and the international recommendations released in Europe [8, 11] and the United States [1, 10]. The registry conductance conforms to the German national guidance on patient registries [12]. In this guidance, an explicit set of requirements both on the study planning, conductance and data analysis is included. The quality assurance of the registry PsoBest follows the recommendations by controlling for structural, process and outcomes quality. The overall supervision of the standard operating procedures for PsoBest based on the guidances was provided by a DIN ISO 9001:2008 certification (certificate ID 170549705). Scientific quality is warranted by a scientific advisory board of German psoriasis experts. Regular annual investigator meetings and quarterly newsletters are provided in order to maintain high quality of investigator performance.

\section{Adverse events}

In this analysis, only prospectively observed events were considered. Any event was classified serious (serious adverse event) in context of in-patient stay, life-threatening circumstances, neoplasms and death. All events observed were divided into 9 classes regarding infections, cardiovascular events and malignancies. Events, which are not matching any class, e.g., gastrointestinal disorders are not shown.

Infections were divided into 'serious'-in the context of in-patient stay or life-threatening status, 'severe'-with antibiotic prescription-and 'non-severe' including all other infections. Major adverse cardiovascular events are defined as irreversible events based on vascular obstruction comprising myocardial infarction, cardiac failure, cardiovascular death, acute coronary syndrome, hemiparesis ischemic stroke and cerebrovascular accident. To prevent loosing important information on cardiovascular events the category other cardiovascular events (right ventricular failure, coronary artery occlusion, cardiac arrest and myocarditis) was defined. Besides these groups no other events occurred regarding infections, cardiovascular events and malignancies. The event-class 'malignancies' comprises all neoplasms with additional regard to melanoma and non-melanoma skin cancer.

MedDRA (Medical Dictionary for Regulatory Activities) preferred terms for investigations as well as for surgical or medical procedures were only considered if they were single reported events, e.g., 'tumor excision' was only counted as event in malignancies if there was no tumor reported.

\section{Data analysis}

The data analyzed in this study were gained in the time period from January 01, 2008 to December 31, 2012. The safety data were separately documented in MedDRA preferred terms for adverse events and severe adverse events.

The occurring events were attributed to the last treatment, applied with a 90-day window following the Manchester template. Only the events of malignancies and death were assigned to all previous systemic treatments, regardless of its exposure time. Events occurring within a combined treatment were assigned to all treatments as exposed.

The absolute number of events was recorded. All safety data reported were referred to exposure time (100 patient 
years). Confidence intervals were computed using inverse Chi-square distribution and significance level 0.05 . Descriptive data comparisons were conducted with safety data from the international Psolar registry [15; Langley $\mathrm{R}$ et al. Malignancy Events in the Psoriasis Longitudinal Assessment and Registry (PSOLAR) Study: Current Status of Observations [unpublished poster presentation] EADV meeting: Prague; 2012; Leonardi C et al. Serious Infection Events in the Psoriasis Longitudinal Assessment and Registry (PSOLAR) Study: Current Status of Observations [unpublished poster presentation] EADV meeting: Prague; 2012; Naldi L et al. Major Adverse Cardiovascular Events (MACE) in The Psoriasis Longitudinal Assessment and Registry (PSOLAR) Study: Current Status of Observations [unpublished talk] EADV meeting: Prague 2012].

The statistical analysis was conducted with IBM SPSS Statistics for Microsoft Windows version 18. Analysis was performed for the groups systemic versus biologic and each single treatment regarding prior exposure to biologics and presence of concomitant conventional systemic therapies.

\section{Results}

\section{Patient cohort}

In total, 2444 patients (40\% women; 634 patients on biologic, 1584 on conventional systemic treatment; 266 patients without qualifying treatment) were included in the analysis. Mean age was 47.4 (SD 14.1) years, the mean duration of disease 18.2 (SD 14.7) years (Table 1). There is a total exposure time to biologics of 1463 years and 1733 to conventional systemic treatments (Table 2). In total, there was a significant rate of comorbidity and co-medication in these patients compared to patients without psoriasis (Fig. 1), indicating a higher risk for adverse events in

Table 1 Clinical patient characteristics of The German Psoriasis Registry PsoBest at baseline and number of adverse events and serious adverse events in the observation time

\begin{tabular}{|c|c|c|c|c|c|c|c|c|c|c|c|c|c|c|c|}
\hline & \multicolumn{5}{|c|}{ Total (2444 patients registered) } & \multicolumn{5}{|c|}{ Biologic treatment (634 patients) } & \multicolumn{5}{|c|}{ Systemic treatment (1584 patients) } \\
\hline & \multicolumn{3}{|c|}{ Number } & \multicolumn{2}{|l|}{$\%$} & \multicolumn{3}{|c|}{ Number } & \multicolumn{2}{|l|}{$\%$} & \multicolumn{2}{|c|}{ Number } & \multicolumn{3}{|c|}{$\%$} \\
\hline Female & \multicolumn{3}{|l|}{975} & \multicolumn{2}{|l|}{39.9} & \multicolumn{3}{|l|}{230} & \multicolumn{2}{|l|}{36.3} & \multicolumn{2}{|l|}{651} & \multicolumn{3}{|c|}{41.1} \\
\hline Male & \multicolumn{3}{|c|}{1.469} & \multicolumn{2}{|l|}{60.1} & \multicolumn{3}{|l|}{404} & \multicolumn{2}{|l|}{63.7} & \multicolumn{2}{|l|}{933} & \multicolumn{3}{|c|}{58.9} \\
\hline \multirow[t]{3}{*}{ Psoriasis-arthritis } & 506 & & & 20.7 & & 230 & & & 36.3 & & 223 & & & 14.1 & \\
\hline & \multicolumn{5}{|c|}{ Total (2444 patients registered) } & \multicolumn{5}{|c|}{ Biologic treatment (634 patients) } & \multicolumn{5}{|c|}{ Systemic treatment (1584 patients) } \\
\hline & Mean & Min & Max & SD & $\begin{array}{l}\text { Valid } \\
\text { measures }\end{array}$ & Mean & Min & $\operatorname{Max}$ & SD & $\begin{array}{l}\text { Valid } \\
\text { measures }\end{array}$ & Mean & Min & $\operatorname{Max}$ & SD & $\begin{array}{l}\text { Valid } \\
\text { measures }\end{array}$ \\
\hline Age (years) & 47.4 & 18.0 & 88.0 & 14.1 & 2438 & 48.0 & 18.0 & 87.0 & 13.3 & 633 & 46.8 & 18.0 & 88.0 & 14.4 & 1580 \\
\hline BMI & 28.2 & 14.7 & 63.3 & 5.8 & 2430 & 28.7 & 15.0 & 54.0 & 5.9 & 629 & 28.0 & 14.7 & 63.3 & 5.8 & 1575 \\
\hline Waist-hip ratio* & 0.9 & 0.6 & 1.4 & 0.1 & 2299 & 0.9 & 0.6 & 1.4 & 0.1 & 593 & 0.9 & 0.6 & 1.3 & 0.1 & 1498 \\
\hline PASI & 14.7 & 0.0 & 64.9 & 9.7 & 2388 & 15.1 & 0.0 & 64.9 & 10.3 & 628 & 14.4 & 0.0 & 64.8 & 9.5 & 1544 \\
\hline DLQI & 11.2 & 0.0 & 30.0 & 7.1 & 2395 & 11.6 & 0.0 & 30.0 & 7.5 & 621 & 10.9 & 0.0 & 30.0 & 6.8 & 1556 \\
\hline BSA & 24.0 & 0.0 & 100.0 & 20.5 & 2379 & 24.3 & 0.0 & 100.0 & 21.0 & 620 & 22.9 & 0.0 & 100.0 & 19.6 & 1545 \\
\hline $\begin{array}{l}\text { Duration of } \\
\text { psoriasis } \\
\text { (years) }{ }^{* *}\end{array}$ & 18.2 & 0.0 & 74.0 & 14.1 & 2312 & 21.9 & 0.0 & 62.0 & 14.1 & 601 & 16.9 & 0.0 & 74.0 & 14.0 & 1500 \\
\hline $\begin{array}{l}\text { Observation time } \\
\text { in registry }(\mathrm{m})^{* *}\end{array}$ & 16.5 & 0.0 & 58.0 & 15.7 & 2444 & 22.0 & 0.0 & 58.0 & 16.2 & 634 & 14.5 & 0.0 & 55.9 & 14.7 & 1584 \\
\hline $\begin{array}{l}\text { Number of adverse } \\
\text { events }\end{array}$ & 1.1 & 0.0 & 14.0 & 1.8 & 2444 & 1.1 & 0.0 & 13.0 & 1.7 & 634 & 1.1 & 0.0 & 14.0 & 1.9 & 1584 \\
\hline $\begin{array}{l}\text { Number of serious } \\
\text { adverse events }\end{array}$ & 0.1 & 0.0 & 8.0 & 0.5 & 2444 & 0.2 & 0.0 & 4.0 & 0.5 & 634 & 0.1 & 0.0 & 8.0 & 0.5 & 1584 \\
\hline
\end{tabular}

Differences between treatment groups are marked

$* p \leq 0.01, * * p \leq 0.001$ 

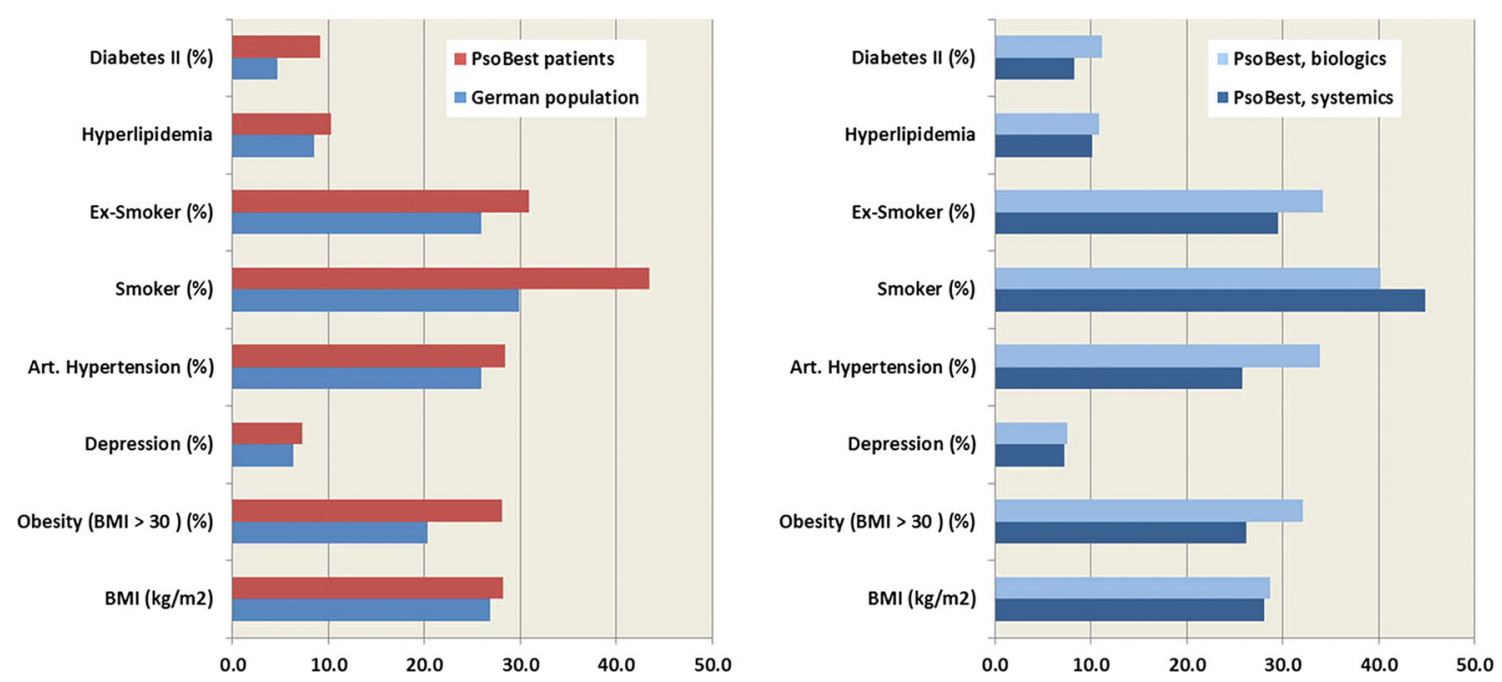

Fig. 1 Rates for comorbidity in patients with psoriasis of the PsoBest registry compared to the age- and gender-adjusted rate of the German normal population (left graph) and comparison between patients started with biologics versus systemic (right graph; $n=2444)$

Table 2 Number of exposed patients and treatment periods including mean and total treatment time

\begin{tabular}{lcrrrrrr}
\hline Exposition & Patients & Periods & \multicolumn{3}{c}{ Exposure time per period $(\mathrm{m})$} & \multirow{2}{*}{ Total exposure time (years) } \\
\cline { 3 - 6 } & & & Mean & Min & Max & SD & \\
\hline Adalimumab & 462 & 480 & 15.6 & 0.0 & 55.3 & 14.2 & 623.0 \\
Etanercept & 298 & 320 & 13.5 & 0.0 & 52.5 & 13.0 & 360.5 \\
Infliximab & 108 & 109 & 14.1 & 0.0 & 48.5 & 12.1 & 127.9 \\
Ustekinumab & 257 & 264 & 16.0 & 0.0 & 44.4 & 13.3 & 351.8 \\
Anti-TNF & 756 & 909 & 14.7 & 0.0 & 55.3 & 13.6 & 1111.4 \\
Biologics & 908 & 1173 & 15.0 & 0.0 & 55.3 & 13.5 & 1463.3 \\
Cyclosporine & 229 & 246 & 7.8 & 0.0 & 50.6 & 9.4 & 160.0 \\
FAE & 981 & 1030 & 9.4 & 0.0 & 55.8 & 11.7 & 807.8 \\
Methotrexate & 798 & 861 & 10.7 & 0.0 & 54.5 & 12.1 & 765.2 \\
Systemics & 1791 & 2137 & 9.7 & 0.0 & 55.8 & 11.6 & 1733.0 \\
\hline
\end{tabular}

patients with psoriasis. Moreover, patients receiving biologics showed significantly higher rates of relevant comorbidities such as cardiovascular disease, obesity and diabetes (Fig. 1).

\section{Drug safety}

\section{Overall rate of serious adverse events}

The overall rate of SAE was 1.3 (SD 0.9) per 100 patient years in systemic and 1.5 (SD 1.2) in biologics ( $p>0.5$, no significant difference).

\section{Rate of infections}

The rate for serious infections was 0.33 (SD 0.20) per 100 patient years in systemic treatments and 0.65 (SD 0.33) in biologic treatments $(p>0.05$, no significant difference;
Fig. 2). Rates of 0.56 (SD 0.27) and 0.59 (SD 0.31) were observed for severe infections and rates for non-severe infections resulted in 4.88 (SD 0.89) in systemic and 7.50 (SD 1.25) in biologics. There were no significant differences between the status of previous exposure to biologics or concomitant conventional systemic therapy in biologic treatments. Patients with previous exposure to biologics receiving systemic therapies had a higher risk for nonsevere infections (12.5 versus 4.5 regarding previous biologics, 12.2 versus 5.4 regarding concomitant systemic, $p<0.05)$.

\section{Major cardiac adverse event}

The MACE rate did not significantly differ between conventional and biologic treatments $(0.56$ (SD 0.27) versus 0.77 (SD 0.36) per 100 patient years) (Fig. 3). Also, there were no significant differences between different single 
Infections (non-severe), as exposed, rate/100 py

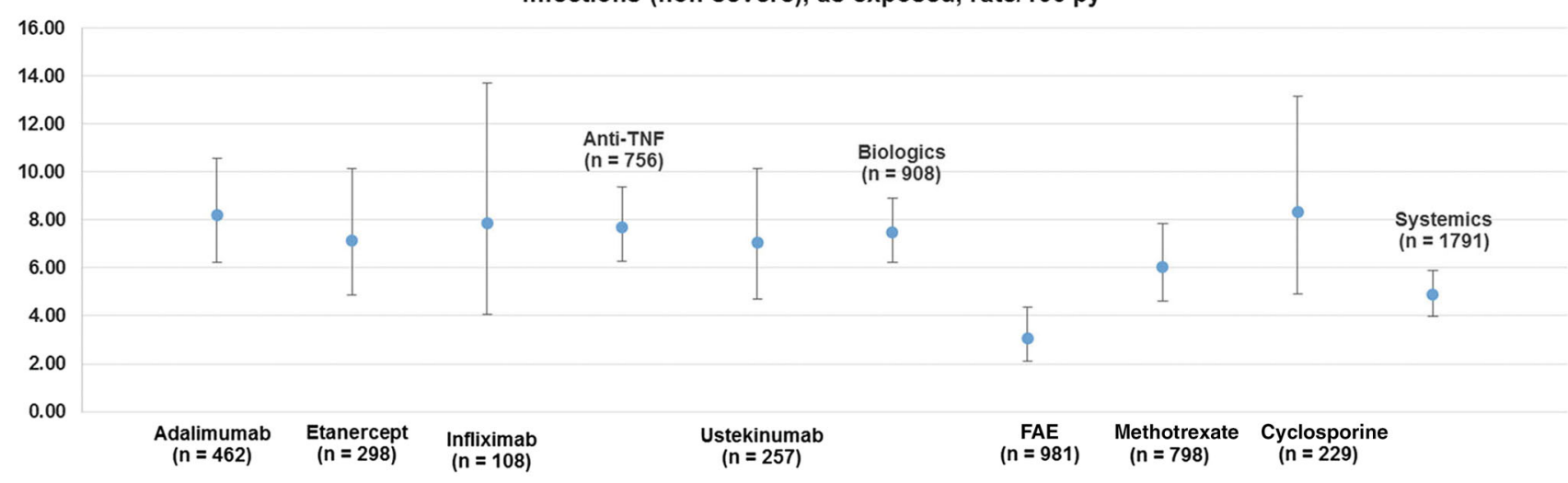

Severe infections, as exposed, rate/100 py

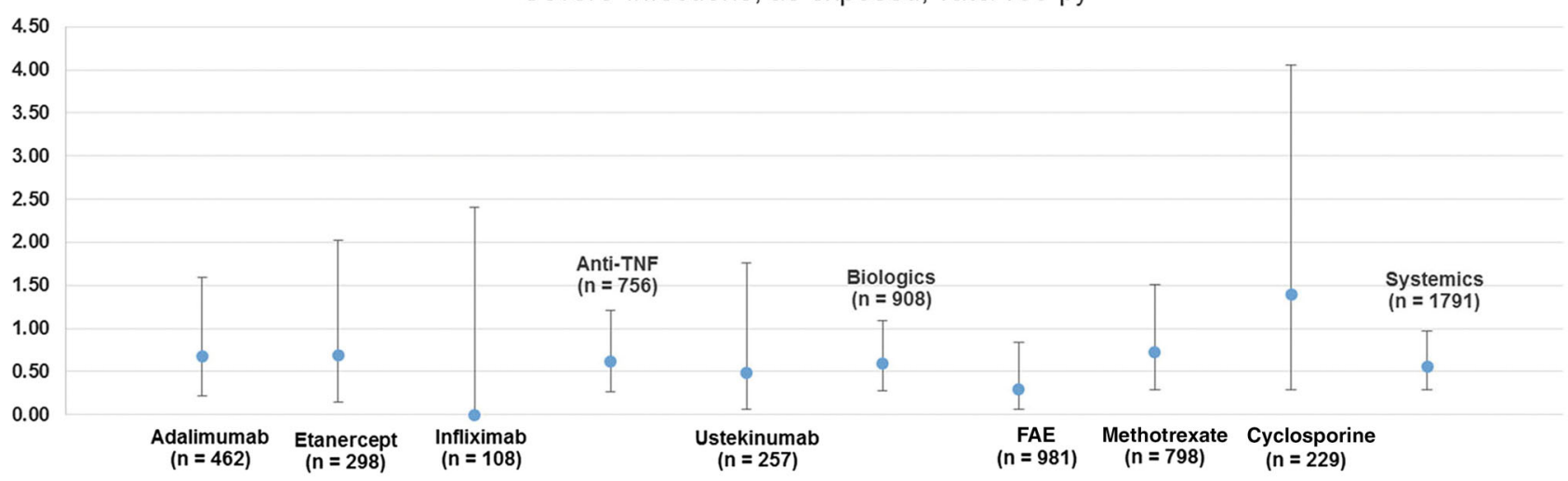

Serious infections, as exposed, rate/100 py

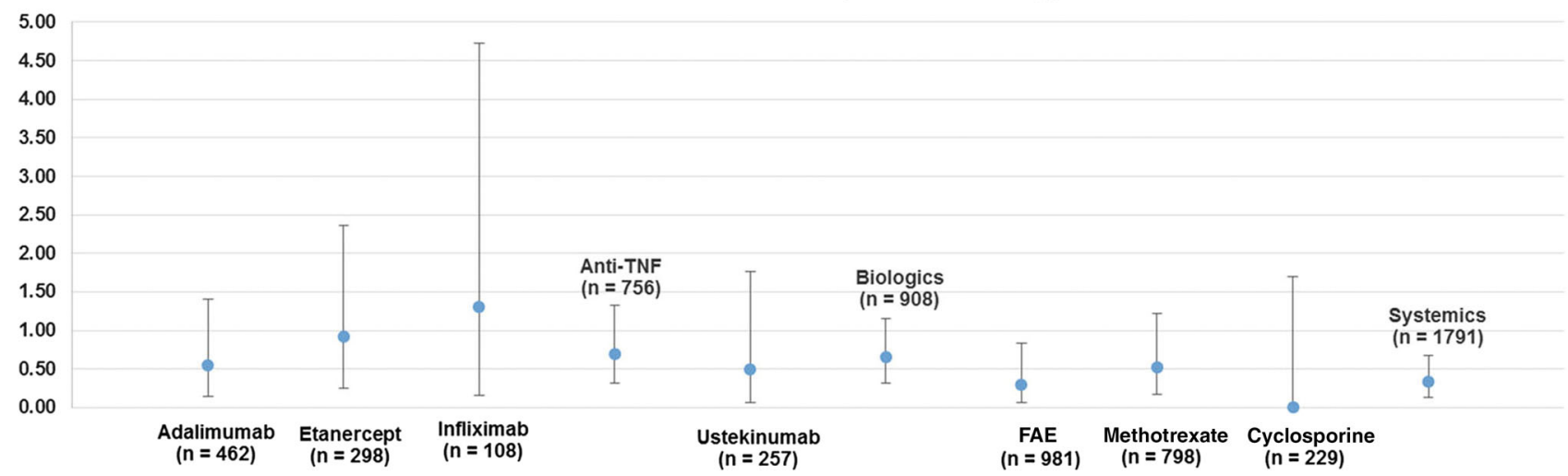

Fig. 2 Rates per 100 patient years of infections (non-severe, severe and serious) in psoriasis patients with systemic and biological drugs $(n=2444)$, bars show confidence interval

drugs. Similarly, the rate of other severe cardiovascular events did not significantly differ between groups.

\section{Rate of malignancies}

The overall rate of malignancies (except NMSC) per 100 patient years was 0.46 (SD 0.24) in patients receiving systemic and 0.49 (SD 0.28) in patients receiving biologics ( $p>0.5$, no significant differences, $n=2444$ ); Fig. 4 . There were no relevant differences between any drugs with respect to "all malignancies except non-melanoma skin cancer", "non-melanoma skin cancer" and "melanoma skin cancer".

\section{Discussion}

Patient treatment registries are large databases reflecting real-world and long-term courses of disease. For psoriasis a series of national registries with comparable data sets has 
MACE, as exposed, rate/100 py

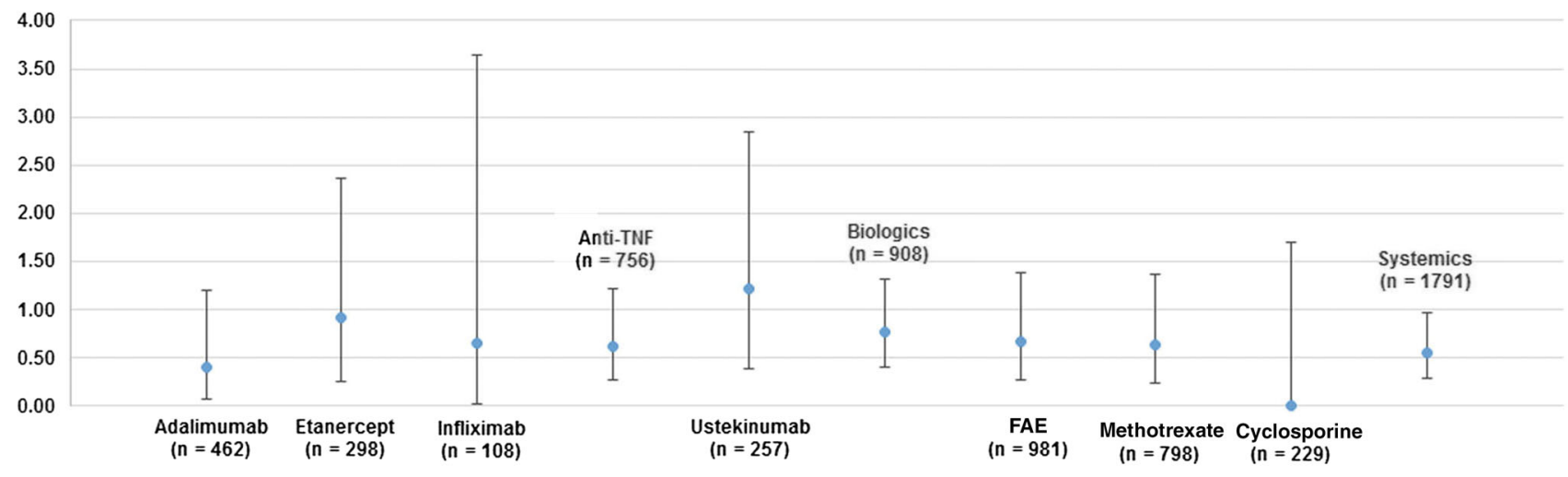

Other severe cardiovascular events, as exposed, rate/100 py

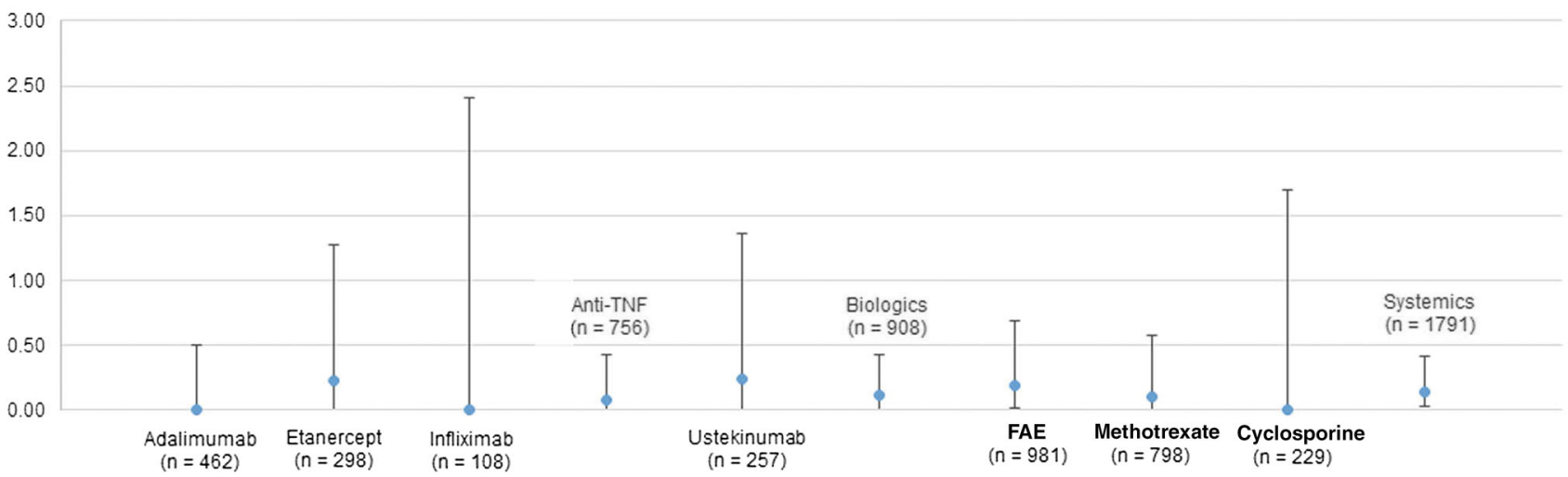

Fig. 3 Rates per 100 patient years of MACE (major cardiac events) and other severe cardiovascular events in psoriasis patients with systemic and biological drugs $(n=2444)$, bars show confidence interval

been established in Europe, in order to gain robust data on safety, tolerability and outcomes of systemic drugs including biologics. The present data analysis from The German Psoriasis Registry PsoBest intended to gain first safety information on antipsoriatic drugs in German routine care. Baseline data indicate that patients in the registry could have a higher risk for cardiovascular complications since comorbidity rates are elevated when compared to age-adjusted population-based rates. This potential bias needs to be considered when analyzing any registry data for safety. If compared to the overall cohort of psoriasis patients, selection events in the registries may occur due to variations in the access to treatments within a country oreven more-between countries [9]; e.g., it is remarkable that in most countries the proportion of women receiving biologics (but not systemic) is much lower than of men. The results of recent publications of psoriasis registries from different countries, however, are in line with our findings, suggesting no increased risk of serious or fatal $\mathrm{AE}$ in biologics compared to conventional systemics [5, 7].

Further limitations of registries derive from the fact that there is no random assignment of treatments. Thus, different treatment groups may show structural inequalities, which can confound results. For this, direct comparisons between drugs are limited, if not adjusted for the inhomogeneities. In the current analysis, no specific adjustments for baseline differences were performed, since the unadjusted outcomes indicate very low rates of safety signals across all treatment arms. Another limiting factor is the limited number of patients included in the analysis. Thus, small differences and rare events may have been missed. Since the inclusions into the registry are ongoing, data analyses will be conducted repeatedly. With respect to generalizability of the data, it needs to be taken into account that the current safety outcomes on patients with moderate-to-severe psoriasis may not be transferable to patients exposed to these drugs with other diseases; e.g., it has been shown that there is a different safety profile for different rheumatologic diseases [6]. Overall, these limitations which are mostly inherent to patient safety registries need to be considered. In contrast, the data's strength is the non-selective character providing external validity and the systematic approach of nationwide solicited real-world safety data acquisition.

In total, with respect to safety signals, there have not been observed any indications for elevated risks of using 
Malignacies (incl. MSC, excl. NMSC), ever exposed, rate/100 py

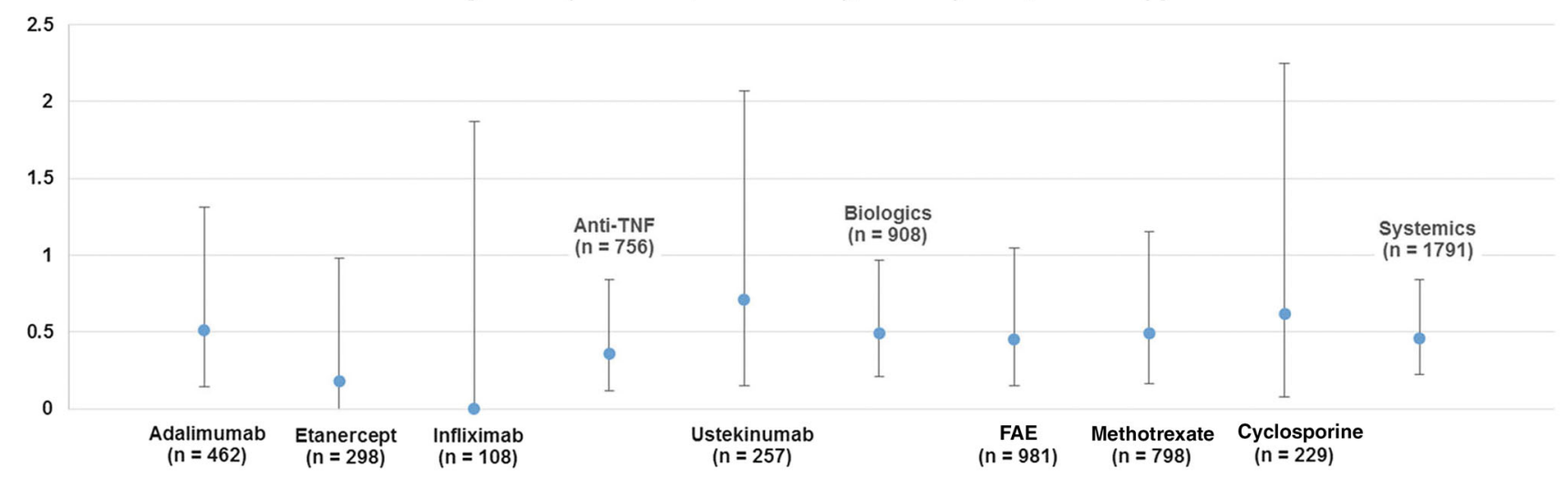

Non-melanoma skin cancer, ever exposed, rate/100 py

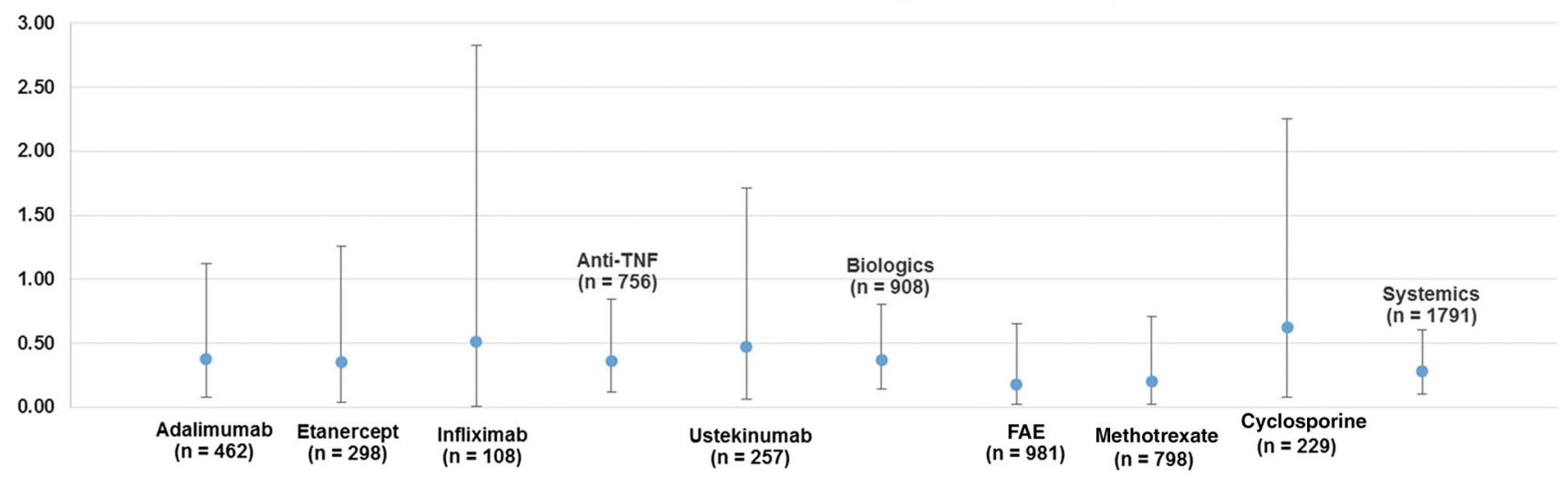

Melanoma skin cancer, ever exposed, rate/100 py

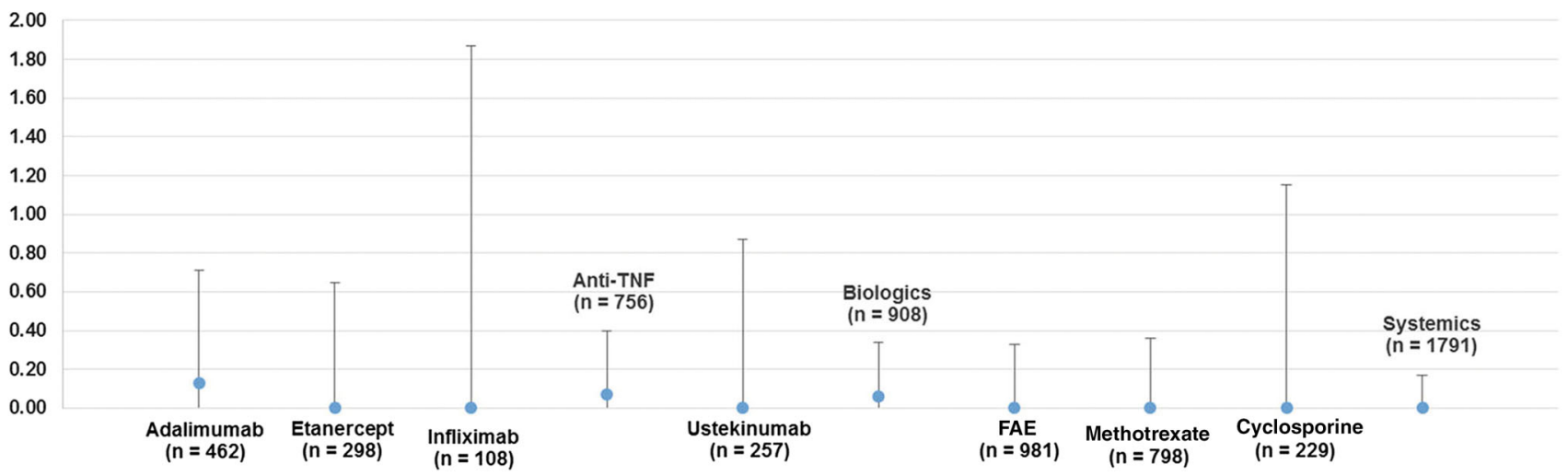

Fig. 4 Rates of malignancies in psoriasis patients with systemic and biological drugs, including all malignancies except non-melanoma skin cancer (top), non-melanoma skin cancer (middle), and melanoma skin cancer (bottom); $n=2444$, bars show confidence interval

systemic or biologic drugs for psoriasis in Germany. When compared to international data, like the Psolar registrywhich mostly recruited patients in North America-the rates for the safety indicators are in the same range. For example, overall rates for neoplasms were $0.5 / 0.5$ for systemic/biologics in PsoBest and 0.6/0.6 in Psolar, all data related to 100 patient years. Similarly, rates for all MACE were 1.0/0.8 in PsoBest and 1.1/1.3 in Psolar. Greater differences, but still on a low level, were found for the rates of overall severe infections (0.6/0.6 in PsoBest and 1.6/1.2 in Psolar). These differences may derive from variations in attributing infection events to non-severe, severe or serious types.

In conclusion, this analysis from The German Psoriasis Registry PsoBest confirms pharmacovigilance data from other registries, indicating a satisfying safety of the systemic and biological drugs used in Germany for moderateto-severe psoriasis. 
Acknowledgments The authors give thanks to the German Dermatological Society ("Deutsche Dermatologische Gesellschaft DDG") and the Professional Association of the German Dermatologists ("Berufsverband der Deutschen Dermatologen BVDD") for the brilliant cooperation. Special thanks goes to all involved centers and patients.

\section{Compliance with ethical standards}

Financial support The register is supported by AbbVie, Biogen (Idec), Janssen-Cilag, medac, MSD, Novartis and Pfizer. These companies do not have any influence on design of the register, data collection and analyses as well as on publication decisions or manuscript constructions.

Conflict of interest U. Mrowietz has been working as an advisor and/or presenter and/or recipient of research support and/or participant at clinical studies for the following companies: Abbott/AbbVie, Almirall-Hermal, Amgen, BASF, Biogen Idec, Celgene, Centocor, Eli Lilly, Forward Pharma, Galderma, Janssen-Cilag, Leo Pharma, medac, MSD, Miltenyi Biotech, Novartis, Pfizer, Teva, VBL, Xenopor. M.A. Radtke has been working as an advisor and/or presenter and/or participant at clinical studies for the following companies: Abbott/Abbvie, Biogen Idec, Janssen-Cilag, medac, MSD, Novartis und Pfizer. D. Thaci has been working as an advisor and/or presenter and/or recipient of research support and/or participant at clinical studies for the following companies: Abbott/AbbVie, Almirall-Hermal, Amgen, Biogen Idec, Celgene, Centocor, Eli Lilly, Forward Pharma, Galderma, Janssen, Leo Pharma, Maruho, Meda, Medac, Mitsubishi Pharma, MSD, Novartis, Pfizer, VBI. M. Augustin has been working as an advisor and/or presenter and/or participant at clinical studies for the following companies: Abbott/AbbVie, Almirall-Hermal, Amgen, Biogen Idec, Celgene, Centocor, Janssen-Cilag, Leo Pharma, medac, MSD (previously Essex, Schering-Plough), Novartis, Pfizer (previously Wyeth). K. Reich, S.J. Rustenbach and C. Spehr do not have any conflict of interest.

Ethical approval All procedures performed in studies involving human participants were in accordance with the ethical standards of the institutional and/or national research committee and with the 1964 Helsinki declaration and its later amendments or comparable ethical standards.

Informed consent Informed consent was obtained from all individual participants included in the study.

Open Access This article is distributed under the terms of the Creative Commons Attribution 4.0 International License (http://crea tivecommons.org/licenses/by/4.0/), which permits unrestricted use, distribution, and reproduction in any medium, provided you give appropriate credit to the original author(s) and the source, provide a link to the Creative Commons license, and indicate if changes were made.

\section{References}

1. Agency EM (2008) Volume 9A of The Rules Governing Medicinal Products in the European Union-Guidelines on Pharmacovigilance for Medicinal Products for Human Use. http:// ec.europa.eu/health/files/eudralex/vol-9/pdf/vol9a_09-2008_en.pdf

2. Augustin M, Glaeske G, Radtke MA, Christophers E, Reich K, Schaefer I (2010) Epidemiology and comorbidity of psoriasis in children. Br J Dermatol 162(3):633-636
3. Augustin M, Reich K, Glaeske G, Schaefer I, Radtke M (2010) Co-Morbidity and age-related prevalence of psoriasis-analysis of health insurance data in Germany. Acta Derm Venereol 90(2):147-151

4. Augustin M, Spehr C, Radtke MA, Boehncke WH, Luger T, Mrowietz U, Reusch M, Strömer K, Wozel G, Kiedrowski RV, Rustenbach SJ, Purwins S, Reich K (2014) German psoriasis registry PsoBest: objectives, methodology and baseline data. J Dtsch Dermatol Ges 12(1):48-57

5. Ahlehoff O, Skov L, Gislason G, Gniadecki R, Iversen L, Bryld LE, Lasthein S, Lindhardsen J, Kristensen SL, Torp-Pedersen C, Hansen PR (2014) Cardiovascular outcomes and systemic antiinflammatory drugs in patients with severe psoriasis: 5-year follow-up of a Danish nationwide cohort. J Eur Acad Dermatol Venereol. doi:10.1111/jdv.12768 [Epub ahead of print]

6. Burmester GR, Panaccione R, Gordon KB, McIlraith MJ, Lacerda AP (2013) Adalimumab: long-term safety in 23,458 patients from global clinical trials in rheumatoid arthritis, juvenile idiopathic arthritis, ankylosing spondylitis, psoriatic arthritis, psoriasis and Crohn's disease. Ann Rheum 72(4):517-524

7. Carretero G, Ferrandiz C, Dauden E, Vanaclocha Sebastián F, Gómez-García FJ, Herrera-Ceballos E, De la Cueva-Dobao P, Belinchón I, Sánchez-Carazo JL, Alsina-Gibert M, López-Estebaranz JL, Ferrán M, Torrado R, Carrascosa JM, Carazo C, Rivera R, Jiménez-Puya R, García-Doval I, BIOBADADERM Study Group (2015) Risk of adverse events in psoriasis patients receiving classic systemic drugs and biologics in a 5-year observational study of clinical practice: 2008-2013 results of the Biobadaderm registry. J Eur Acad Dermatol Venereol 29(1):156-163

8. European Network of Centres for Pharmacoepidemiology and Pharmacovigilance (2013) European Medicines Agency. http:// www.encepp.eu. Accessed 27 Mar 2013

9. Garcia-Doval I, Rustenbach SJ, Stern R, Dam TN, Cohen AD, Baker C, Spuls PI, Naldi L, Network Psonet (2013) Systemic psoriasis therapy shows high between-country variation: a sign of unwarranted variation? Cross-sectional analysis of baseline data from the PSONET registries. Br J Dermatol 169(3):710-714

10. Glicklich R, Dreyer N (2010) Registries for evaluating patient outcomes: a user's guide. In: 2nd (edn) Agency for Healthcare Research and Quality (US), Rockville (MD). http://www.ncbi. nlm.nih.gov/books/NBK49444/pdf/TOC.pdf

11. (ISPE) ISoP (2008) Guidelines for good pharmacoepidemiology practices (GPP). Pharmacoepidemiol Drug Saf 17:200-208

12. Mueller D, Augustin M, Banik N, Baumann W, Bestehorn K, Kieschke J, Lefering R, Maier B, Mathis S, Rustenbach SJ, Sauerland S, Semler SC, Stausberg J, Sturm H, Unger C, Neugebauer EA (2010) Memorandum registry for health services research. Gesundheitswesen 72(11):824-839

13. Nast A, Boehncke WH, Mrowietz U, Ockenfels HM, Philipp S, Reich K, Rosenbach T, Sammain A, Schlaeger M, Sebastian M, Sterry W, Streit V, Augustin M, Erdmann R, Klaus J, Koza J, Mueller S, Orzechowski HD, Rosumeck S, Schmid-Ott G, Weberschock T, Rzany B (2012) German S3-Guidelines on the Treatment of Psoriasis Vulgaris (Short Version). Arch Dermatol Res 304(2):87-113

14. Ormerod AD, Augustin M, Baker C, Chosidow O, Cohen AD, Dam TN, Garcia-Doval I, Lecluse LL, Schmitt-Egenolf M, Spuls PI, Watson KD, Naldi L (2012) Challenges for synthesising data in a network of registries for systemic psoriasis therapies. Dermatology 224(3):236-243

15. Papp KA, Strober B, Augustin M, Calabro S, Londhe A, Chevrier M, PSOLAR investigators and Steering Committee (2012) PSOLAR: design, utility, and preliminary results of a prospective, international, disease based registry of patients with psoriasis who are receiving, or are candidates for, conventional 
systemic treatments or biologic agents. J Drugs Dermatol 11(10):1210-1217

16. Pathirana D, Ormerod AD, Saiag P, Smith C, Spuls PI, Nast A, Barker J, Bos JD, Burmester GR, Chimenti S, Dubertret L, Eberlein B, Erdmann R, Ferguson J, Girolomoni G, Gisondi P, Giunta A, Griffiths C, Hönigsmann H, Hussain M, Jobling R, Karvonen SL, Kemeny L, Kopp I, Leonardi C, Maccarone M, Menter A, Mrowietz U, Naldi L, Nijsten T, Ortonne JP, Orzechowski HD, Rantanen T, Reich K, Reytan N, Richards H, Thio HB, van de Kerkhof P, Rzany B (2009) European S3-guidelines on the systemic treatment of psoriasis vulgaris. J Eur Acad
Dermatol Venereol 23(Suppl 2):1-70. doi:10.1111/j.1468-3083. 2009.03389.x

17. PsoNet. European Registry of Psoriasis [Internet]. Centro Studi GISED. Available via internet. http://www.psonet.eu/cms/public/ files/psonet-protocol.pdf. Accessed 27 Mar 2013

18. Schmitt-Egenolf M (2006) Psoriasis therapy in real life: the need for registries. Dermatology 213:327-330

19. Zink A, Listing J, Klindworth C, Zeidler H, German Collaborative Arthritis Centres (2001) The national database of the German Collaborative Arthritis Centres: I. Structure, aims, and patients. Ann Rheum Dis 60(3):199-206 